\title{
Reactivity of astrocytes in hippocampal CA1 area in rats after administration of habanero peppers
}

\author{
Jadwiga Jaworska-Adamu' ${ }^{1}$, Aleksandra Krawczyk ${ }^{1}$, Karol Rycerz ${ }^{1}$, Marcin Golynski² \\ ${ }^{1}$ Department of Animal Anatomy and Histology, Faculty of Veterinary Medicine, \\ University of Life Sciences, Lublin, Poland \\ ${ }^{2}$ Faculty of Biological and Veterinary Sciences, Nicolaus Copernicus University in Torun, Torun, \\ Poland
}

\begin{abstract}
Introduction. Astrocytes react to microenvironmental changes. Their reactivity is manifested by an increase in glial fibrillary acidic protein (GFAP) and $\mathrm{S} 100 \beta$ protein levels, hypertrophy and hyperplasia. The aim of the study was to analyse immunoreactive GFAP (GFAP-IR) and S100 $\beta$ (S100 $\beta$-IR) astrocytes of hippocampal CA1 area in adult rats intragastrically (i.g.) treated with habanero peppers.

Material and methods. Brains from 10 control rats (group C) and 10 rats receiving oil suspension of habanero fruits for 7 days (group I-7) or 28 days (group II-28) were used. Antibodies against GFAP and S100 $\beta$ were used for immunohistochemistry. Morphology and distribution of astrocytes was evaluated under light microscope and their density was quantitatively analysed.

Results. In the CA1 hippocampal area of group II-28 rats, GFAP-IR cells with numerous, branched processes were observed. S100 $\beta$-IR astrocytes had delicate, single processes in comparison with cells without processes observed in groups I-7 and C. In groups I-7 and II-28, GFAP-IR astrocytes' density significantly increased in SR - stratum radiatum of hippocampal CA1 area. In group I-7, a density of cells with the expression of $\mathrm{S} 100 \beta$ was significantly increased in SO - stratum oriens layer. In group II-28, the density of S100 $\beta$-IR astrocytes was decreased.

Conclusions. Habanero peppers administrated to rats, especially for a longer time, caused reactive changes in the astrocytes in hippocampal CA1 area, and thus these glial cells may protect neurons against excitotoxic damage. (Folia Histochemica et Cytobiologica 2021, Vol. 59, No. 1, 1-7)
\end{abstract}

Key words: rat; hippocampus; CA1; astrocytes; GFAP; S100 $\beta$; capsaicin; IHC

\section{Introduction}

Astrocytes of the central nervous system (CNS) are necessary for the proper functioning of the brain. These cells are the structural and metabolic support for neurons. They regulate the extracellular concentration of ions, metabolites, and neurotransmitters in the CNS. Astroglia is also the source of many com-

Correspondence address: Aleksandra Krawczyk, $\mathrm{PhD}$

Department of Animal Anatomy and Histology,

Faculty of Veterinary Medicine,

University of Life Sciences,

Akademicka St. 12, 20-033 Lublin, Poland

e-mail: aleksandra.krawczyk@up.lublin.pl pounds that affect neuronal and synaptic plasticity, e.g. during the induction of long-term potentiation (LTP). In addition, it plays an important role in neurogenesis and synaptogenesis [1-4]. In the course of physiological and pathological processes astrocytes dynamically react to changes in their microenvironment. Their reactivity is manifested by increased expression and synthesis of various proteins, e.g. the glial fibrillary acidic protein (GFAP) and $\mathrm{S} 100 \beta$ protein. Furthermore, overgrowth of cell bodies and cytoplasmic processes (hypertrophy), and glial proliferation (hyperplasia) are observed [5, 6]. Many different endogenous and exogenous factors lead to the reactivity of the astrocytes. Stimulation of the glia is also influenced by diet and living conditions of animals

This article is available in open access under Creative Common Attribution-Non-Commercial-No Derivatives 4.0 International (CC BY-NC-ND 4.0) license, allowing to download articles and share them with others as long as they credit the authors and the publisher, but without permission to change them in any way or use them commercially. 
$[7,8]$. In the CA1 area of the hippocampus of mice housed for 8 weeks in the enriched environment, e.g. with various toys, tunnels, hideouts, astroglial hypertrophy was observed [8]. Increased synthesis of GFAP and glutamine synthetase (GS) has been shown in the arcuate nucleus and the median eminence in rats treated subcutaneously with capsaicin (CAP) [9]. CAP is an alkaloid contained in habanero peppers (Capsicum chinense Jacq.) which, due to spicy taste, are often used as culinary additive. Capsaicin has analgesic, antibacterial and antioxidant characteristics. At low doses, it is characterized by low toxicity, but in large amounts it can have an adverse effect on the body. After intravenous or subcutaneous administration, this alkaloid can be detected in an unchanged form in the CNS. CAP binds to neuronal receptors and astrocytic vanilloid 1 receptor (TRPV1). Some authors suggested that TRPV1 affects the synaptic plasticity in the hippocampal CA1 area [10-13]. Furthermore, it was found that the stimulation of TRPV1 receptor can lead to excessive activity of pyramidal neurons and the induction of seizures. Such a phenomenon is observed in response to a high temperature that activates TRPV1 during fever [11].

The hippocampus controls various mechanisms that affect the animal behaviour. This brain area is involved in learning and memory processes, which depend on inter alia induction of LTP. Neurons of hippocampal CA1 area form a characteristic, four-layered arrangement. Stratum oriens (SO) contains basket cells and axons of pyramidal neurons which bodies are present in the stratum pyramidale (SP), dendrites in the stratum radiatum (SR), and their endings are located in the stratum lacunosum moleculare (SLM) $[14,15]$. So far, intragastric (i.g.) administration of habanero peppers, as well as the CAP, has not been studied in hippocampal astroglia. The aim of the study was to carry out morphological and quantitative analyses of GFAP-immunoreactive (GFAP-IR) and S100 $\beta$-immunoreactive (S100 $\beta$-IR) astrocytes of hippocampal CA1 area of rats treated intragastrically with habanero peppers at various periods of time.

\section{Material and methods}

The experiments were approved by the Second Local Ethics Committee in Lublin (No. 21/2013). A total of 20 male Wistar rats (120-125 g) were used for the study. Animals were housed in an air-conditioned room with a relative humidity of $45-47 \%$ and a temperature of $22-23^{\circ} \mathrm{C}$ in $12 \mathrm{~h}$ light/12 h dark cycles. Rats were fed with commercial feed for laboratory animals (LSM, Agropol Motycz Poland) with permanent access to water ad libitum. The period of acclimatization before experiments was 16 days, and the duration of experiment was 7 or 28 days. The animals were randomly divided into two study groups which received habanero peppers, i.e. I-7 and II-28, and their respective controls (C-7, C-28). Every $12 \mathrm{~h}$, approx. $0.5 \mathrm{ml}$ of pure peanut oil was administrated to rats in the control groups and rats from groups I-7 and II-28 received the oily suspension of the grounded dried habanero peppers (containing $7.64 \mathrm{mg} / \mathrm{d} . \mathrm{m}$. capsaicin and dihydrocapsaicin) at a dose of $0.08 \mathrm{~g} \mathrm{d.m./kg} \mathrm{b.w.} \mathrm{After}$ the experiment, all animals were euthanized. Then, the brains were dissected and fixed in buffered $10 \%$ formalin $(\mathrm{pH} 7.0)$ for $12 \mathrm{~h}$ at $4^{\circ} \mathrm{C}$. The material was embedded in paraffin blocks using routine histological techniques. For further analyses frontal $6 \mu \mathrm{m}$-thick sections containing hippocampus were used (A $4230 \mu \mathrm{m}$ - A $3750 \mu \mathrm{m}$, according to the atlas by König and Klippel) [16].

\section{Staining by the indirect peroxidase-antiperoxidase (PAP)} method. Immunochemical reactions were performed on deparaffinised and rehydrated sections prepared from each animal. For the inhibition of the reactivity of endogenous peroxidase $3 \% \mathrm{H}_{2} \mathrm{O}_{2}$ was used for $30 \mathrm{~min}$ at room temperature (RT). Then, in order to remove background colouring, sections were treated with $10 \%$ goat serum (G9023; SigmaAldrich, St. Louis, MO, USA) for $20 \mathrm{~min}$. A set of antibodies (SigmaAldrich) and reagents diluted in $0.5 \mathrm{M}$ TRIS buffer (TBS) at $\mathrm{pH} 7.6$ according to the manufacturer's instructions were used for the immunostaining. To reveal astrocytic proteins a monoclonal rabbit anti-glial fibrillary acidic protein (GFAP, 1:400 G9269 SigmaAldrich) antibody and mouse anti-S100 $\beta$ protein $(1: 1000$ S2532; SigmaAldrich) antibody were used. Incubation of the material with these antibodies was carried out for $24 \mathrm{~h}$ at $4{ }^{\circ} \mathrm{C}$. Afterwards, species appropriate secondary $\operatorname{IgG}-$ peroxidase antibody (1:400 A9169 SigmaAldrich) was used for $1 \mathrm{~h}$ at RT. Diaminobenzidine (DAB, SigmaAldrich) was used as chromogen. Successively, the preparations were counterstained with Mayer's haematoxylin. GFAP-IR and S100 $\beta$-IR astrocytes of CA1 area were observed and photographed under light microscope Olympus BX 51 (Olympus, Tokyo, Japan) with Olympus Color View IIIu digital camera. Based on the immunoreactivity for GFAP and $\mathrm{S} 100 \beta$ the morphology of the astrocytes and their distribution in the different layers of the hippocampal CA1 area were analysed [17].

Quantitative and statistical analyses. The mean density of GFAP and $\mathrm{S} 100 \beta$ immunopositive cells were analysed in layers of hippocampal CA1 area using Cell^ ${ }^{\wedge} \mathrm{D}$ programme (Olympus). For each examined protein, 5 sections from each animal were randomly selected. Next, two photomicrographs of the hippocampal CA1 area were taken from each section. A grid of squares of $150 \mu \mathrm{m} \times 150 \mu \mathrm{m}$ 
$\left(22.5 \times 10^{-3} \mathrm{~mm}^{2}\right)$ was imposed on the photographs. The size of the squares was selected in a way that the test area was the same for all layers of the studied regions. Only the squares which entirely covered the studied layer were chosen for counting. GFAP-IR and S100 $\beta$-IR astrocytes were counted in two randomly chosen squares of the grid. Finally, 100 measurements of GFAP-IR and S100 $\beta$-IR astrocytes density were collected from each group. Statistical analyses were performed using R 3.0.2 programme. Means were compared by the one-way analysis of variance (ANOVA) and the Tukey HSD post hoc test. The normal distribution of data was assessed using the Shapiro-Wilk test. The data that did not meet the condition of normal distribution was compared using the non-parametric Kruskall-Wallis test. The significance factor of all tests was set to $\alpha=0.05$.

\section{Results}

\section{Microscopic analysis of the GFAP-IR and S100 $\beta-I R$ astrocytes of the hippocampal CA1 area}

The duration of the experiment had no effect on the results obtained in the control groups; hence, the data obtained for groups C-7 and C-28 were consolidated and presented together as one control group (C). In the hippocampal CA1 area, all the examined groups of animals (C, I-7 and II-28) showed GFAP-IR and S100 $\beta$-IR cells. The greatest accumulation of astrocytes expressing both proteins was observed in the SLM (Figs. 1 A-C, 2 A-C). In group II-28 in all layers of the CA1 area GFAP-IR astrocytes were characterized by numerous and branched processes (Fig. 1C). In groups $\mathrm{C}$ and I-7 S100 $\beta$-IR astrocytes without processes were observed in the SO, SP, SR, and SLM of hippocampal CA1 area (Fig. 2 A, B). However, in the group II-28 some part of S100 $\beta$-IR astrocytes were similar to those observed in groups $\mathrm{C}$ and $\mathrm{I}-7$, and the rest of cells had a delicate, branched processes extending from their bodies (Fig. 2C).

\section{Quantitative analyses of GFAP-IR and S100 $\beta$-IR astrocytes of the hippocampal CA1 area}

The density of GFAP-IR astrocytes did not differ significantly between control and I-7, II-28 groups of animals in most layers of the CA1 area of the hippocampus. A statistically significant increase in cell density was demonstrated only in SR of CA1 area in both I-7 and II-28 groups (Fig. 3).

The density of S100 $\beta$-IR astrocytes was comparable in SP and SR layers of CA1 area in all examined individuals. The density of S100 $\beta$-IR astrocytes in SO of hippocampal CA1 area was significantly increased in group I-7 rats. However, in the SLM the number of S100 $\beta$-IR astrocytes significantly decreased in the studied group II-28 of animals (Fig. 4).

\section{Discussion}

These studies, carried out with use of antibodies against GFAP and S100 $\beta$, demonstrated differential reactivity of glia in the hippocampal CA1 area of rats after 7 and 28 days of treatment with habanero
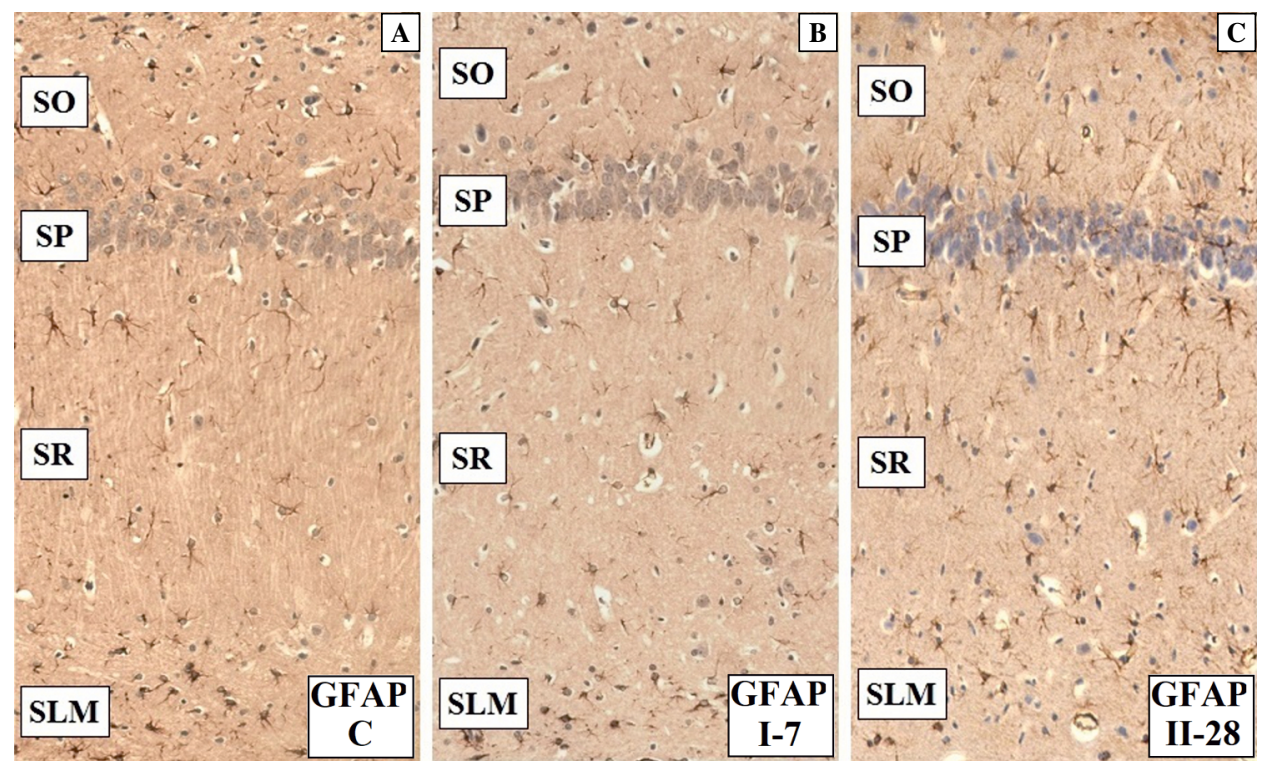

Figure 1. The GFAP-immunoreactive (-IR) astrocytes in rat hippocampal CA1 area of control (C), and animals which received habanero pepper for 7 or 28 days (groups I-7, II-28, respectively). SO — stratum oriens, SP — stratum pyramidale, SR — stratum radiatum, SLM — stratum lacunosum moleculare. Magnification approx. 200×. 


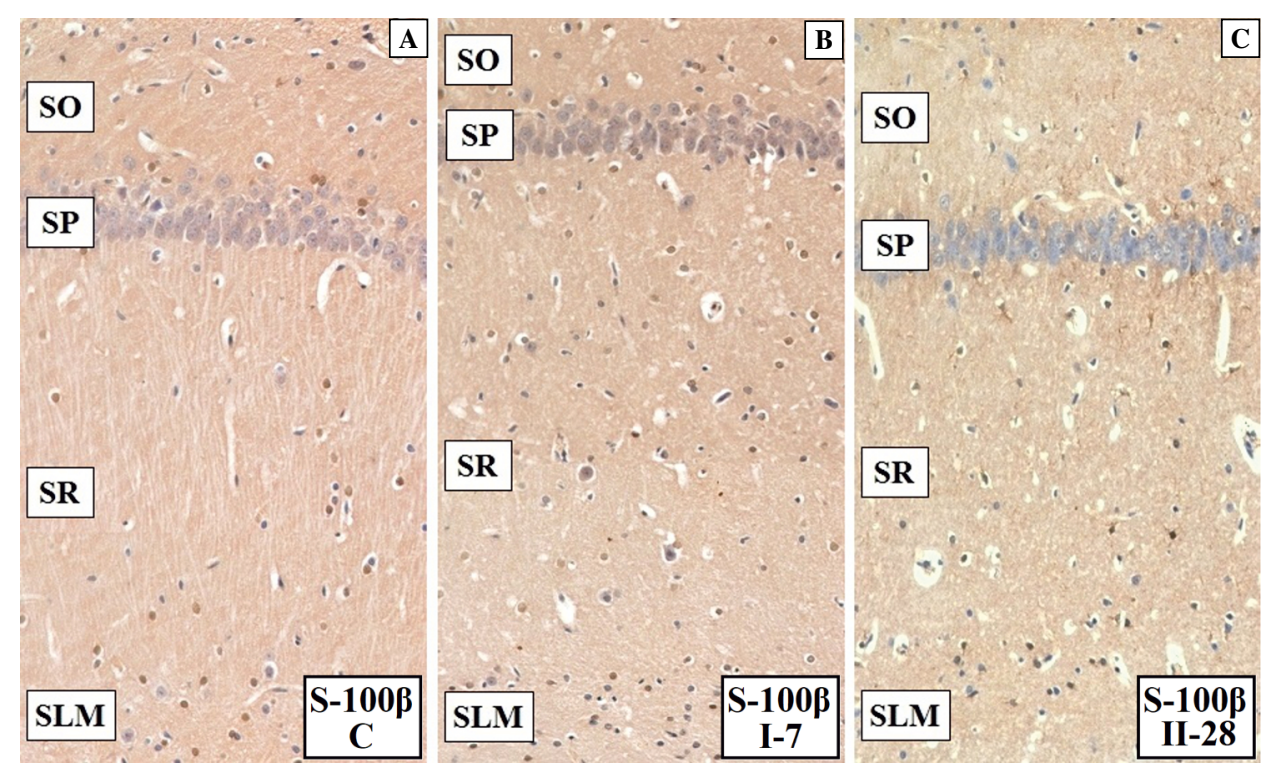

Figure 2. The S100 $\beta$-IR astrocytes in rat hippocampal CA1 area of control (C), I-7 and II-28 groups; Abbreviations as in the legends of Figure 1. Magnification approx. 200×.

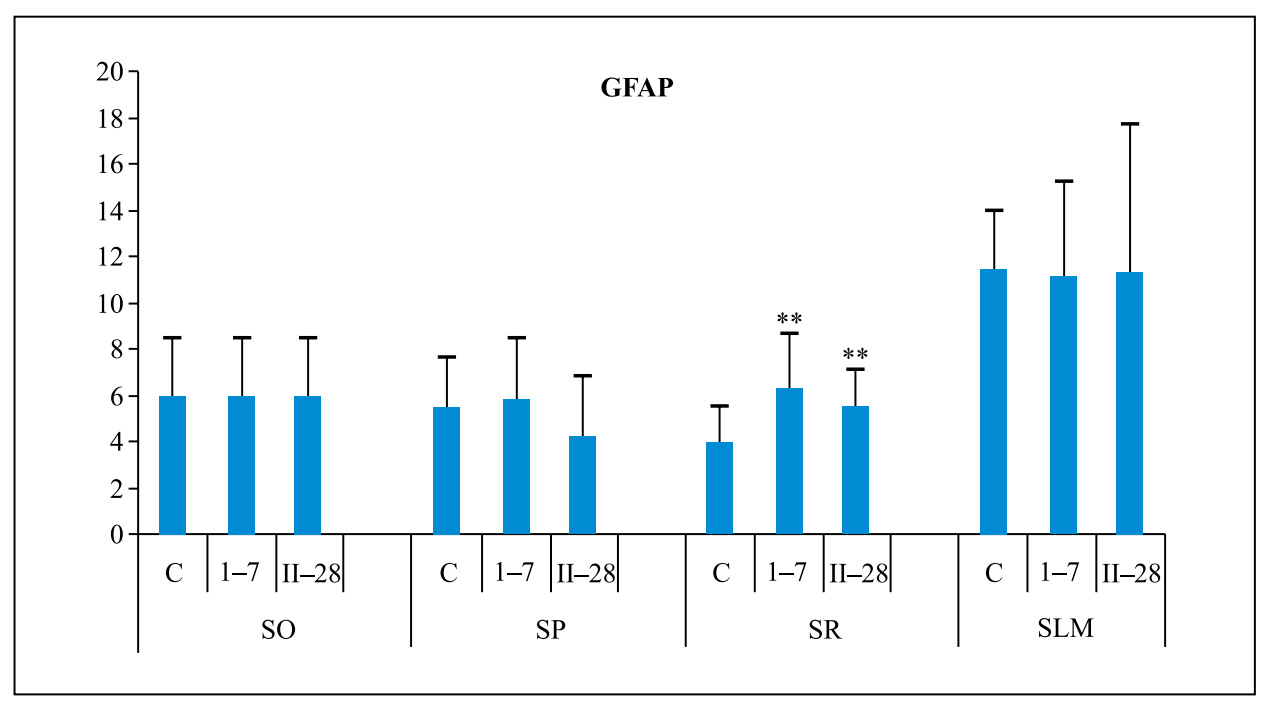

Figure 3. The density of GFAP-IR cells in CA1 area of hippocampus in control (C) and experimental (I-7, II-28) rats. Data shows mean density of GFAP-immunopositive cells in the area of $2.5 \times 10^{-3} \mathrm{~mm}^{2}$ as described in Methods. Bars represent standard deviation; ** $p<0.05$, statistically significant difference between control group and experimental groups (I-7, II-28) (Kruskal-Wallis test). Abbreviations as in the legends of Figure 1.

peppers. The most significant alterations were seen in hippocampal GFAP-IR astrocytes in animals of group II-28. In all layers of CA1 area most cells demonstrated stellate shapes and branched processes. In addition, morphological changes were accompanied by an increase in the density of GFAP-IR astrocytes in layer SR, which was also observed in animals treated with habanero peppers for 7 days. This increase may be a result of the modification of the phenotypic astrocytes in which an overproduction of GFAP, increased for- mation of intermediate glial filaments and stability of lengthening processes occurred. GFAP is a marker for nearly all of the reactive cells. Nonreactive astroglia contains this protein at a level which is undetectable by immunohistochemical methods [18]. The observed overgrowth of astrocytic processes may be associated with increased activity of CA1 pyramidal neurons. $\mathrm{Nu}-$ merous studies have shown that capsaicin modulates synaptic plasticity of CA1 area pyramidal neurons by the activation of TRPV1 receptors in neurons of CA3 


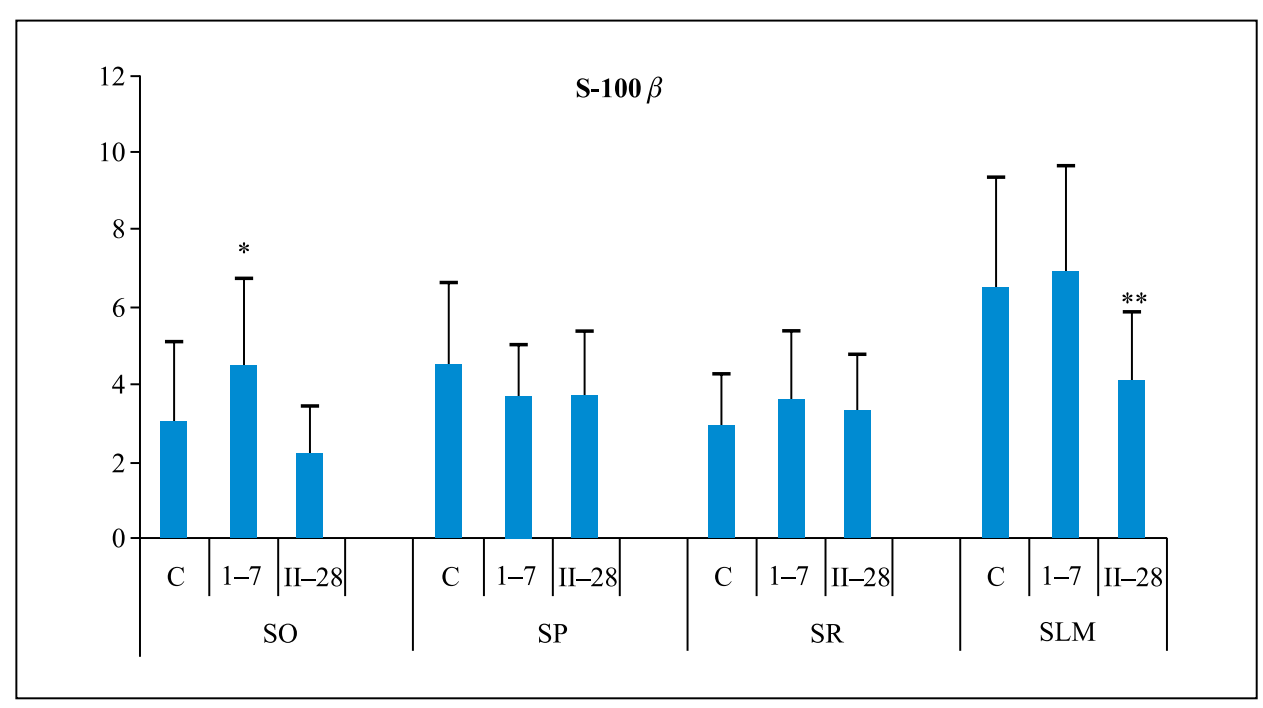

Figure 4. The density of S100 $\beta$-IR cells in CA1 area of hippocampus in control (C) and experimental (I-7, II-28) rats. Data shows mean density of $\mathrm{S} 100 \beta$-IR cells in the area of $2.5 \times 10^{-3} \mathrm{~mm}^{2}$ as described in Methods. Bars represent standard deviation; statistically significant difference between control group and experimental groups (I-7, II-28) related to the same layer: ${ }^{*} p<0.05$ (ANOVA), ${ }^{* *} p<0.05$ (Kruskal-Wallis). Abbreviations as in the legend to Figure 1.

area. Schaffer's collaterals contact with the dendrites of the major cells and interneurons in SR of CA1 area. CAP inhibits the release of glutamate (Glu) from the CA3 neurons to interneurons. However, this alkaloid does not affect the synapses located between the main cells. Therefore, administration of TRPV1 agonists results in a disinhibition of CA1 area pyramidal neurons, an increase in their activation, and thus enhanced induction of LTP $[10,19,20]$. LTP is one of the forms of synaptic plasticity. Initiation and maintenance of LTP are associated with an increase in dendritic branching. Increasing the receptive surface of neurons contributes to the strengthening of excitatory transmission in pyramidal neurons of the CA1 area $[21,22]$.

Intense neuronal activity leads to an increase in GFAP mRNA and the expression of this protein in astrocytes [23]. GFAP plays an important role in the interactions between astroglia and neuronal cells. Changes in its production affect synaptic functions, Glu and glutamine metabolism, and the concentration of ions [24]. Astrocytic processes limit the spread of neurotransmitters released into the synaptic clefts thereby maintaining proper neurotransmission. Moreover, they are highly mobile and are able to extend in the direction of the newly formed or existing synapses releasing Glu [25]. Synaptogenesis and hyperplasia of glial processes were observed in the rat hippocampal CA1 area, among others, in invoked convulsions model [26]. An abnormal synaptic plasticity which was accompanied by increased activation of astrocytes was shown during the formation of epileptic focus [26-28]. This is probably related to the necessity of excessive Glu uptake in order to protection of other nerve structures against exitotoxic damage. Transport of glutamate is carried out through specific glial transporter. Some results indicate the colocalization of glial glutamate transporter (GLT-1) with intermediate glial filaments of the astroglia, as well as participation of the cytoskeleton in movement of the transporter along the extensions of the astrocytes [29, 30]. Furthermore, GFAP is involved in anchoring glial glutamate and aspartate transporter (GLAST) in the cell membrane of astrocytes. Hence, it plays an important role in strengthening the transport of glutamate [31]. Glu uptake from the synaptic cleft is modulated, among others, by $\mathrm{S} 100 \beta$ protein present in the extracellular space and produced by reactive astrocytes [32, 33]. Active release of this protein takes place, e.g. via stimulation of the Glu metabotropic receptors from group II (mGluR 3), as shown in the hippocampus of a mouse epilepsy model [34]. Increased secretion of S100 $\beta$ protein to the extracellular space results in a decrease in the number of cells immunoreactive for the protein. This can explain the decreased density of astrocytes observed in our study in the SLM layer of the hippocampal CA1area of group II-28 of rats. This reaction may be due to the initiation of the mechanisms enhancing the removal of excess glutamate from the newly formed and existing synaptic connections, most likely for neuroprotection [35-38]. 
To summarise, our findings provide evidence that the habanero pepper administered intragastrically, especially for a longer period of time, affects the activity of hippocampal astrocytes. Increased expression of GFAP and hypertrophy of astrocytic processes is a sign of glial reactivity. This phenomenon may be a part of the mechanisms which allow astrocytes to better control and regulate synaptic microenvironment, and thus protect neurons from excitotoxicity. Structural changes in the astrocytic network could, therefore, play a role in hippocampal synaptic plasticity in animals after the administration of habanero pepper.

\section{References}

1. Artinian J, Jordan A, Khlaifia A, et al. Regulation of hippocampal memory by mTORC1 in somatostatin interneurons. J Neurosci. 2019; 39(43): 8439-8456, doi: 10.1523/JNEUROSCI.0728-19.2019, indexed in Pubmed: 31519824.

2. Guerra-Gomes S, Sousa N, Pinto L, et al. Functional roles of astrocyte calcium elevations: from synapses to behavior. Front Cell Neurosci. 2017; 11: 427, doi: 10.3389/fncel.2017.00427, indexed in Pubmed: 29386997.

3. Ota Y, Zanetti AT, Hallock RM. The role of astrocytes in the regulation of synaptic plasticity and memory formation. Neural Plast. 2013; 2013: 185463, doi: 10.1155/2013/185463, indexed in Pubmed: 24369508.

4. Verkhratsky A, Nedergaard M. Physiology of Astroglia. Physiol Rev. 2018; 98(1): 239-389, doi: 10.1152/physrev.00042.2016, indexed in Pubmed: 29351512.

5. Landis DM. The early reactions of non-neuronal cells to brain injury. Annu Rev Neurosci. 1994; 17: 133-151, doi: 10.1146/ annurev.ne.17.030194.001025, indexed in Pubmed: 8210172.

6. Siracusa R, Fusco R, Cuzzocrea S. Astrocytes: Role and functions in brain pathologies. Front Pharmacol. 2019; 10: 1114, doi: 10.3389/fphar.2019.01114, indexed in Pubmed: 31611796.

7. Cano V, Valladolid-Acebes I, Hernández-Nuño F, et al. Morphological changes in glial fibrillary acidic protein immunopositive astrocytes in the hippocampus of dietary-induced obese mice. Neuroreport. 2014; 25(11): 819-822, doi: 10.1097/ WNR.000000000000180, indexed in Pubmed: 24911388.

8. Viola GG, Rodrigues L, Américo JC, et al. Morphological changes in hippocampal astrocytes induced by environmental enrichment in mice. Brain Res. 2009; 1274: 47-54, doi: 10.1016/j.brainres.2009.04.007, indexed in Pubmed: 19374889.

9. Okere CO, Waterhouse BD. Capsaicin increases GFAP and glutamine synthetase immunoreactivity in rat arcuate nucleus and median eminence. Neuroreport. 2004; 15(2): 255-258, doi: 10.1097/00001756-200402090-00008, indexed in Pubmed: 15076747.

10. Bennion D, Jensen T, Walther C, et al. Transient receptor potential vanilloid 1 agonists modulate hippocampal CA1 LTP via the GABAergic system. Neuropharmacology. 2011; 61(4): 730-738, doi: 10.1016/j.neuropharm.2011.05.018, indexed in Pubmed: 21645527.

11. Gibson HE, Edwards JG, Page RS, et al. TRPV1 channels mediate long-term depression at synapses on hippocampal interneurons. Neuron. 2008; 57(5): 746-759, doi: 10.1016/j. neuron.2007.12.027, indexed in Pubmed: 18341994.

12. Rycerz K, Krawczyk A, Jaworska-Adamu J, et al. Immunoreactivity of arcuate nucleus astrocytes in rats after intragastric administration of habanero peppers (Capsicum Chinese
Jacq.). Pol J Vet Sci. 2016; 19(4): 809-817, doi: 10.1515/pjvs2016-0102, indexed in Pubmed: 28092615.

13. Thompson RJ. A direct demonstration of functional TRPV1 in Cajal-Retzius cells. J Physiol. 2018; 596(16): 3451-3452, doi: 10.1113/JP276521, indexed in Pubmed: 29920677.

14. El Falougy H, Kubikova E, Benuska J. The microscopical structure of the hippocampus in the rat. Bratisl Lek Listy. 2008; 109(3): 106-110, indexed in Pubmed: 18517132.

15. Knierim JJ. The hippocampus. Curr Biol. 2015; 25(23): R1116-R1121, doi: 10.1016/j.cub.2015.10.049, indexed in Pubmed: 26654366.

16. König JFR, Klippel RAA. stereotactic atlas of the forebrain and lower parts of the brain stem. Williams and Wilkins: Baltimore; 1963.

17. Krawczyk A, Jaworska-Adamu J. Reactivity of astrocytes in the periaqueductal gray matter of rats treated with monosodium glutamate. Folia Histochem Cytobiol. 2020; 58(2): 147-155, doi: 10.5603/FHC.a2020.0010, indexed in Pubmed: 32495938.

18. Kimelberg HK. The problem of astrocyte identity. Neurochem Int. 2004; 45(2-3): 191-202, doi: 10.1016/j.neuint.2003.08.015, indexed in Pubmed: 15145537.

19. Hurtado-Zavala JI, Ramachandran B, Ahmed S, et al. TRPV1 regulates excitatory innervation of OLM neurons in the hippocampus. Nat Commun. 2017; 8: 15878, doi: 10.1038/ ncomms15878, indexed in Pubmed: 28722015.

20. Li HB, Mao RR, Zhang JC, et al. Antistress effect of TRPV1 channel on synaptic plasticity and spatial memory. Biol Psychiatry. 2008; 64(4): 286-292, doi: 10.1016/j.biopsych.2008.02.020, indexed in Pubmed: 18405883.

21. Magó Á, Weber JP, Ujfalussy BB, et al. Synaptic plasticity depends on the fine-scale input pattern in thin dendrites of CA1 pyramidal neurons. J Neurosci. 2020; 40(13): 2593-2605, doi: 10.1523/JNEUROSCI.2071-19.2020, indexed in Pubmed: 32047054.

22. Ruan YW, Zou B, Fan Y, et al. Dendritic plasticity of CA1 pyramidal neurons after transient global ischemia. Neuroscience. 2006; 140(1): 191-201, doi: 10.1016/j.neuroscience.2006.01.039, indexed in Pubmed: 16529877.

23. Steward O, Torre ER, Tomasulo R, et al. Neuronal activity up-regulates astroglial gene expression. Proc Natl Acad Sci U S A. 1991; 88(15): 6819-6823, doi: 10.1073/pnas.88.15.6819, indexed in Pubmed: 1862105.

24. Middeldorp J, Hol EM. GFAP in health and disease. Prog Neurobiol. 2011; 93(3): 421-443, doi: 10.1016/j.pneurobio.2011.01.005, indexed in Pubmed: 21219963.

25. Barker AJ, Ullian EM. Astrocytes and synaptic plasticity. Neuroscientist. 2010; 16(1): 40-50, doi: 10.1177/1073858409339215, indexed in Pubmed: 20236948.

26. Hawrylak N, Chang FL, Greenough WT. Astrocytic and synaptic response to kindling in hippocampal subfield CA1. II. Synaptogenesis and astrocytic process increases to in vivo kindling. Brain Res 1993; 603: 309-316. doi: 10.1016/00068993(93)91252-n, indexed in Pubmed: 8461983.

27. Armstrong DD. The neuropathology of temporal lobe epilepsy. J Neuropathol Exp Neurol. 1993; 52(5): 433-443, doi: 10.1097/00005072-199309000-00001, indexed in Pubmed: 8360697.

28. Bezprozvanny I, Mattson MP. Neuronal calcium mishandling and the pathogenesis of Alzheimer's disease. Trends Neurosci. 2008; 31(9): 454-463, doi: 10.1016/j.tins.2008.06.005, indexed in Pubmed: 18675468.

29. Shobha K, Vijayalakshmi K, Alladi PA, et al. Altered in-vitro and in-vivo expression of glial glutamate transporter-1 following exposure to cerebrospinal fluid of amyotrophic lateral sclerosis patients. J Neurol Sci. 2007; 254(1-2): 9-16, doi: 10.1016/j.jns.2006.12.004, indexed in Pubmed: 17254611. 
30. Zhou J, Sutherland ML. Glutamate transporter cluster formation in astrocytic processes regulates glutamate uptake activity. J Neurosci. 2004; 24(28): 6301-6306, doi: 10.1523/ JNEUROSCI.1404-04.2004, indexed in Pubmed: 15254085.

31. Sullivan SM, Sullivan RKP, Miller SM, et al. Phosphorylation of GFAP is associated with injury in the neonatal pig hypoxic-ischemic brain. Neurochem Res. 2012; 37(11): 2364-2378, doi: 10.1007/s11064-012-0774-5, indexed in Pubmed: 22528834.

32. Michetti F, D'Ambrosi N, Toesca A, et al. The S100B story: from biomarker to active factor in neural injury. $\mathrm{J}$ Neurochem. 2019; 148(2): 168-187, doi: 10.1111/jnc.14574, indexed in Pubmed: 30144068.

33. Tramontina F, Tramontina AC, Souza DF, et al. Glutamate uptake is stimulated by extracellular S100B in hippocampal astrocytes. Cell Mol Neurobiol. 2006; 26(1): 81-86, doi: 10.1007/ s10571-006-9099-8, indexed in Pubmed: 16633903.

34. Sakatani S, Seto-Ohshima A, Shinohara Y, et al. Neural-activity-dependent release of S100B from astrocytes enhances kainate-induced gamma oscillations in vivo. J Neurosci. 2008; 28(43): 10928-10936, doi: 10.1523/JNEUROSCI.3693-08.2008, indexed in Pubmed: 18945900.
35. Abdel-Salam OME, Sleem AA, Sayed MA, et al. Capsaicin exerts anti-convulsant and neuroprotective effects in pentylenetetrazole-induced seizures. Neurochem Res. 2020; 45(5): 1045-1061, doi: 10.1007/s11064-020-02979-3, indexed in Pubmed: 32036609.

36. Donato R. Intracellular and extracellular roles of S100 proteins. Microsc Res Tech. 2003; 60(6): 540-551, doi: 10.1002/ jemt.10296, indexed in Pubmed: 12645002.

37. Huang M, Cheng G, Tan H, et al. Capsaicin protects cortical neurons against ischemia/reperfusion injury via down-regulating NMDA receptors. Exp Neurol. 2017; 295: 66-76, doi: 10.1016/j.expneurol.2017.05.001, indexed in Pubmed: 28479337.

38. Yasuda Y, Tateishi N, Shimoda T, et al. Relationship between S100beta and GFAP expression in astrocytes during infarction and glial scar formation after mild transient ischemia. Brain Res. 2004; 1021(1): 20-31, doi: 10.1016/j.brainres.2004.06.015, indexed in Pubmed: 15328028.

Submitted: 30 January, 2020 Accepted after reviews: 18 September, 2020 Available as AoP: 27 January, 2021 